\title{
Fluorescence Studies on New Potential Antitumoral Benzothienopyran-1-ones in Solution and in Liposomes
}

\author{
Elisabete M. S. Castanheira • M. Solange D. Carvalho • \\ Daniel J. G. Soares • Paulo J. G. Coutinho • \\ Ricardo C. Calhelha • Maria-João R. P. Queiroz
}

Received: 27 October 2009 / Accepted: 7 February 2010

(C) Springer Science+Business Media, LLC 2010

\begin{abstract}
Fluorescence properties of four new potential antitumoral compounds, 3-arylbenzothieno[2,3-c]pyran-1ones, were studied in solution and in lipid membranes of dipalmitoyl phosphatidylcholine (DPPC), egg yolk phosphatidylcholine (Egg-PC) and dioctadecyldimethylammonium bromide (DODAB). The 3-(4-methoxyphenyl)benzothieno [2,3-c]pyran-1-one (1c) exhibits the higher fluorescence quantum yields in all solvents studied. All compounds present a solvent sensitive emission, with significant red shifts in polar solvents for the methoxylated compounds. The results point to an ICT character of the excited state, more pronounced for compound 1c. Fluorescence (steady-state) anisotropy measurements of the compounds incorporated in liposomes of DPPC, DODAB and Egg-PC indicate that all compounds have two different locations, one due to a deep penetration in the lipid membrane and another corresponding to a more hydrated environment. In general, the methoxylated compounds prefer hydrated environments inside the liposomes. The 3-(4fluorophenyl)benzothieno[2,3-c]pyran-1-one (1a) clearly prefers a hydrated environment, with some molecules located at the outer part of the liposome interface. On the contrary, the preferential location of 3-(2-fluorophenyl)benzothieno[2,3-c] pyran-1-one (1) is in the region of lipid hydrophobic tails. Compounds with a planar geometry (1a and 1c) have higher mobility in the lipid membranes when phase transition occurs.
\end{abstract}

E. M. S. Castanheira $(\bowtie) \cdot$ M. S. D. Carvalho $\cdot$ D. J. G. Soares P. J. G. Coutinho

Centro de Física (CFUM), Universidade do Minho,

Campus de Gualtar,

4710-057 Braga, Portugal

e-mail: ecoutinho@fisica.uminho.pt

M. S. D. Carvalho • R. C. Calhelha • M.-J. R. P. Queiroz Centro de Química (CQ-UM), Universidade do Minho,

Campus de Gualtar,

4710-057 Braga, Portugal
Keywords Benzothienopyran-1-ones · Antitumoral compounds $\cdot$ Liposomes $\cdot$ Fluorescence anisotropy
Abbreviations
DPPC Dipalmitoyl phosphatidylcholine
DODAB Dioctadecyldimethylammonium bromide
Egg-PC Egg yolk phosphatidylcholine
PC Phosphatidylcholine

\section{Introduction}

Our research group has been interested in the synthesis and in the photophysical behavior, in solution and in lipid membranes, of novel heteroaromatic biological active compounds [1-3].

Recently, some of us have described the synthesis of new 3-(aryl)benzothieno[2,3-c]pyran-1-ones from 3-bromobenzo $[b]$ thiophene-2-carboxylic acid and different arylphenylacetylenes [4] (compounds 1a-c, Fig. 1). Compound 1d, with a methoxy group in the ortho position relative to the pyranone ring (Fig. 1) was synthesized in this work (Scheme 1) for comparison, and the synthesis is described below.

Compounds 1a-c were evaluated for their capacity to inhibit the in vitro growth of three human tumor cell lines, MCF-7 (breast adenocarcinoma), NCI-H460 (non-small cell lung cancer) and SF-268 (CNS cancer). Compound 1b was shown to be the most potent against the three cell lines tested, presenting low $\mathrm{GI}_{50}$ (the lowest concentration causing $50 \%$ of the cell growth inhibition after a continuous exposure of $48 \mathrm{~h}$ ) values $(12-19 \mu \mathrm{M})$ [4].

These results suggested us to perform fluorescence studies of compounds 1a-d incorporated in liposomes. The photophysical properties in solution and in lipid vesicles of DPPC (dipalmitoyl phosphatidylcholine), Egg-PC (egg yolk phosphatidylcholine) and of the cationic lipid DODAB (dioctadecyldimethylammonium bromide) were studied. The 
phospholipids DPPC and phosphatidylcholine (from egg yolk) are neutral components of biological membranes, while cationic liposomes based in DODAB have been used as vehicles for DNA transfection and drug delivery [5-7]. Fluorescence (steady-state) anisotropy measurements were also performed to obtain further information about the location of these compounds in lipid membranes.

\section{Experimental}

Synthesis

General The melting point $\left({ }^{\circ} \mathrm{C}\right)$ was determined on a SMP3 Stuart apparatus. ${ }^{1} \mathrm{H}$ and ${ }^{13} \mathrm{C}$ NMR spectra were recorded on a Bruker Avance $\mathrm{II}^{+}$at 400 and $100.6 \mathrm{MHz}$, respectively. Chemical shifts $(\delta)$ are given in ppm. MS (EI) spectrum and HRMS on the $\mathrm{M}^{+}$were recorded by the mass spectrometry service of the University of Vigo, Spain. Petroleum ether refers to the boiling range $40-60{ }^{\circ} \mathrm{C}$.

3-(2-methoxyphenyl)benzothieno[2,3-c]pyran-1-one (1d) 3Bromo-benzo[b]thiophene-2-carboxylic acid (100 mg, $0.390 \mathrm{mmol})$, 2-methoxyphenylacetylene (1.2 equiv.) $\mathrm{PdCl}_{2}\left(\mathrm{PPh}_{3}\right)_{2}(5 \mathrm{~mol} \%), \mathrm{CuI}(3 \mathrm{~mol} \%)$, and $\mathrm{NEt}_{3}$ (3 equiv.) were added under argon to dry DMF $(2 \mathrm{~mL})$ in a dry Schlenk tube and the mixture was heated for $2 \mathrm{~h}$ at $100{ }^{\circ} \mathrm{C}$. After cooling, water $(5 \mathrm{~mL})$ and ethyl acetate $(5 \mathrm{~mL})$ were added and the phases were separated. The aqueous phase was then extracted with more ethyl acetate $(3 \times 5 \mathrm{~mL})$ and the organic phases were collected, dried $\left(\mathrm{MgSO}_{4}\right)$ and filtered. The solvent removal gave a solid which was crystallized from $\mathrm{CH}_{2} \mathrm{Cl}_{2} /$ petroleum ether affording $\mathbf{1 d}$ as a beige solid (95 mg, 80\%), m.p. 191-193 ${ }^{\circ} \mathrm{C} .{ }^{1} \mathrm{H}-\mathrm{NMR}$ (400 MHz, DMSO-d 6 ) $\delta 3.98(3 \mathrm{H}, \mathrm{s}, \mathrm{OMe}), 7.11-7.15(1 \mathrm{H}$, $\mathrm{m}, \mathrm{ArH}), 7.23-7.25(1 \mathrm{H}, \mathrm{m}, \mathrm{ArH}), 7.48-7.53(1 \mathrm{H}, \mathrm{m}$, ArH), 7.62-7.66 (1H, m, ArH), 7.70-7.74 (1H, m, ArH), 7.80-7.83 (1H, m, ArH), 7.99 (1H, s, 4-H), 8.21-8.24 (1H, m, ArH), 8.43-8.45 (1H, m, ArH) ppm. ${ }^{13} \mathrm{C}-\mathrm{NMR}(100.6 \mathrm{MHz}$, DMSO- $\left.d_{6}\right) \delta 55.30\left(\mathrm{OCH}_{3}\right), 101.83(\mathrm{CH}), 112.26(\mathrm{CH})$, $120.02(\mathrm{C}), 120.73(\mathrm{CH}), 121.20(\mathrm{C}), 123.92(\mathrm{CH}), 124.69$ $(\mathrm{CH}), 125.79(\mathrm{CH}), 128.63(\mathrm{CH}), 129.61(\mathrm{CH}), 131.69$ (CH), 134.10 (C), 142.46 (C), 144.07 (C), 154.26 (C), 157.06 (C), 158.08 (C) ppm. MS (EI): m/z $308\left(\mathrm{M}^{+}, 100\right)$, $280\left(\mathrm{M}^{+}-28,59\right)$. HRMS M${ }^{+}$calc. for $\mathrm{C}_{18} \mathrm{H}_{12} \mathrm{O}_{3} \mathrm{~S}: 308.0507$, found: 308.0508 .

Spectroscopic studies

\section{Materials and methods}

All the solutions were prepared using spectroscopic grade solvents and ultrapure water (Milli-Q grade). 1,2-Dipalmitoylsn-glycero-3-phosphocholine (DPPC) and 1,2-Diacyl-snglycero-3-phosphocholine from egg yolk (Egg-PC), from Sigma-Aldrich, and dioctadecyldimethylammonium bromide (DODAB), from Tokyo Kasei, were used as received (lipid structures are shown below).<smiles>CCCCCCCCCCCCCCCCCCCCCCCC(=O)OC[C@H](COP(=O)([O-])OCC[N+](C)(C)C)OC(=O)CCCC</smiles><smiles>[R]C(=O)OCCOC[C@H]([2H])OP(=O)([O-])OCC[N+](C)(C)C</smiles>

Egg-PC

$R_{1}, R_{2}=$ fatty acid residues

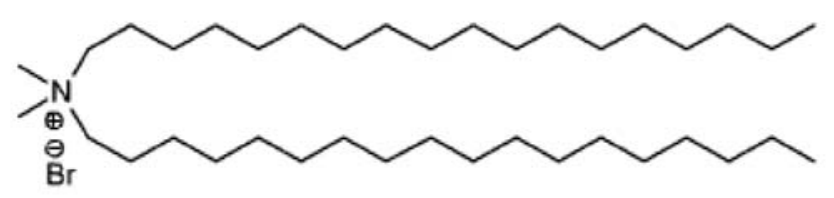

DODAB 
<smiles>[R]c1ccc(-c2cc3c(sc4ccccc43)c(=O)o2)c([R])c1</smiles>

1a $R^{1}=F, R^{2}=H$

1b $R^{1}=H, R^{2}=F$

1c $\mathrm{R}^{1}=\mathrm{OMe}, \mathrm{R}^{2}=\mathrm{H}$

1d $R^{1}=H, R^{2}=O M e$

Fig. 1 Structure of 3-(aryl)benzothieno[2,3-c]pyran-1-ones

For Egg-PC vesicles preparation, defined volumes of a stock solution of lipid (34.5 mM) and compound (0.2 mM) in ethanol were injected together, under vigorous stirring, to an aqueous buffer solution (10 mM Tris, $\mathrm{pH}=7.4)$, at room temperature. A similar procedure was adopted for DPPC and DODAB liposomes, but the injection of the required amounts of stock solutions of lipid (50 mM for DPPC and $20 \mathrm{mM}$ for DODAB) and compound in ethanol was done at $60{ }^{\circ} \mathrm{C}$, well above the melting transition temperature of both lipids, $c a .41^{\circ} \mathrm{C}$ for DPPC [8] and $45^{\circ} \mathrm{C}$ for DODAB [9]. In all cases, the final lipid concentration was $1 \mathrm{mM}$, with compounds 1a-d/lipid molar ratio of 1:500.

\section{Spectroscopic measurements}

Absorption spectra were recorded in a Shimadzu UV3101PC UV-Vis-NIR spectrophotometer. Fluorescence measurements were performed using a Spex Fluorolog 3 spectrofluorimeter, equipped with double monochromators in both excitation and emission, Glan-Thompson polarizers and a temperature-controllable cuvette holder. Fluorescence spectra were corrected for the instrumental response of the system.

For fluorescence quantum yield determination, the solutions were previously bubbled for $20 \mathrm{~min}$ with ultrapure nitrogen. The fluorescence quantum yields $\left(\Phi_{\mathrm{s}}\right)$ were determined using the standard method (Eq. 1) [10, 11]. Anthracene in ethanol $\left(\Phi_{\mathrm{r}}=0.27\right.$ at $25{ }^{\circ} \mathrm{C}$ [12]) and quinine sulfate in $0.05 \mathrm{M} \mathrm{H}_{2} \mathrm{SO}_{4}\left(\Phi_{\mathrm{r}}=0.546\right.$ at $25{ }^{\circ} \mathrm{C}[13$, 14]) were used as references.

$\Phi_{\mathrm{s}}=\frac{A_{\mathrm{r}} F_{\mathrm{s}} n_{\mathrm{s}}^{2}}{A_{\mathrm{s}} F_{\mathrm{r}} n_{\mathrm{r}}^{2}} \Phi_{\mathrm{r}}$

where $A$ is the absorbance at the excitation wavelength, $F$ the integrated emission area and $n$ the refraction index of the solvents used. Subscripts refer to the reference (r) or sample (s) compound.

The steady-state fluorescence anisotropy, $r$, is calculated by

$r=\frac{I_{\mathrm{VV}}-G I_{\mathrm{VH}}}{I_{\mathrm{VV}}+2 G I_{\mathrm{VH}}}$ where $I_{\mathrm{VV}}$ and $I_{\mathrm{VH}}$ are the intensities of the emission spectra obtained with vertical and horizontal polarization, respectively (for vertically polarized excitation light), and $G=$ $I_{\mathrm{HV}} / I_{\mathrm{HH}}$ is the instrument correction factor, where $I_{\mathrm{HV}}$ and $I_{\mathrm{HH}}$ are the emission intensities obtained with vertical and horizontal polarization (for horizontally polarized excitation light).

\section{Data analysis}

Solvatochromic shifts were described by the LippertMataga Eq. (3), which relates the energy difference between absorption and emission maxima to the orientation polarizability, $[15,16]$

$\bar{v}_{\mathrm{abs}}-\bar{v}_{\mathrm{fl}}=\frac{1}{4 \pi \varepsilon_{0}} \frac{2 \Delta \mu^{2}}{h c R^{3}} \Delta f+$ const

where $\bar{v}_{\text {abs }}$ is the wavenumber of maximum absorption, $\bar{v}_{\mathrm{fl}}$ is the wavenumber of maximum emission, $\Delta \mu=\mu_{\mathrm{e}}-\mu_{\mathrm{g}}$ is the difference in the dipole moment of solute molecule between excited $\left(\mu_{\mathrm{e}}\right)$ and ground $\left(\mu_{\mathrm{g}}\right)$ states, $R$ is the cavity radius (considering the fluorophore a point dipole at the center of a spherical cavity immersed in the homogeneous solvent), and $\Delta f$ is the orientation polarizability given by (Eq. 4):

$$
\Delta f=\frac{\varepsilon-1}{2 \varepsilon+1}-\frac{n^{2}-1}{2 n^{2}+1},
$$

where $\varepsilon$ is the static dielectric constant and $n$ the refractive index of the solvent.

Fluorescence anisotropy components $\left(I_{\mathrm{VV}}\right.$ and $\left.\mathrm{G} \cdot I_{\mathrm{VH}}\right)$ were globally fitted to two sums of lognormal components (Eqs. 5 and 6) [17], each sum characterized by a fitted anisotropy value,

$$
\begin{aligned}
I_{\mathrm{VV}}= & \sum_{\mathrm{i}} \frac{A_{1 \mathrm{i}}}{\left(\lambda-\left(\lambda_{\max }\right)_{1 \mathrm{i}}+a_{1 \mathrm{i}}\right)} \exp \left(-c_{1 \mathrm{i}}^{2}\right) \\
& \exp \left\{-\frac{1}{2 c_{1 \mathrm{i}}^{2}}\left[\ln \left(\frac{\lambda-\left(\lambda_{\max }\right)_{1 \mathrm{i}}+a_{1 \mathrm{i}}}{b_{1 \mathrm{i}}}\right)\right]^{2}\right\}+ \\
& +\sum_{\mathrm{i}} \frac{A_{2 \mathrm{i}}}{\left(\lambda-\left(\lambda_{\max }\right)_{2 \mathrm{i}}+a_{2 \mathrm{i}}\right)} \exp \left(-c_{2 \mathrm{i}}^{2}\right) \\
& \exp \left\{-\frac{1}{2 c_{2 \mathrm{i}}^{2}}\left[\ln \left(\frac{\lambda-\left(\lambda_{\max }\right)_{2 \mathrm{i}}+a_{2 \mathrm{i}}}{b_{2 \mathrm{i}}}\right)\right]^{2}\right\}
\end{aligned}
$$

$$
\begin{aligned}
G \cdot I_{\mathrm{VH}}= & \sum_{\mathrm{i}} \frac{A_{1 \mathrm{i}}^{\prime}}{\left(\lambda-\left(\lambda_{\max }\right)_{1 \mathrm{i}}+a_{1 \mathrm{i}}\right)} \exp \left(-c_{1 \mathrm{i}}^{2}\right) \\
& \exp \left\{-\frac{1}{2 c_{1 \mathrm{i}}^{2}}\left[\ln \left(\frac{\lambda-\left(\lambda_{\max }\right)_{1 \mathrm{i}}+a_{1 \mathrm{i}}}{b_{1 \mathrm{i}}}\right)\right]^{2}\right\}+ \\
& +\sum_{\mathrm{i}} \frac{A_{2 \mathrm{i}}^{\prime}}{\left(\lambda-\left(\lambda_{\max }\right)_{2 \mathrm{i}}+a_{2 \mathrm{i}}\right)} \exp \left(-c_{2 \mathrm{i}}^{2}\right) \\
& \exp \left\{-\frac{1}{2 c_{2 \mathrm{i}}^{2}}\left[\ln \left(\frac{\lambda-\left(\lambda_{\max }\right)_{2 \mathrm{i}}+a_{2 \mathrm{i}}}{b_{2 \mathrm{i}}}\right)\right]^{2}\right\}
\end{aligned}
$$




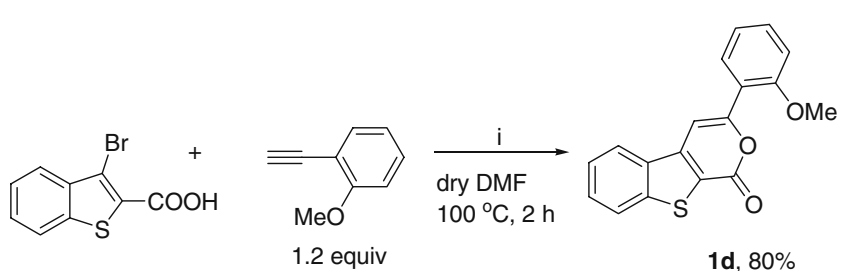

i) $\mathrm{PdCl}_{2}\left(\mathrm{PPh}_{3}\right)_{2}(5 \mathrm{~mol} \%) \mathrm{Cul}(3 \mathrm{~mol} \%), \mathrm{NEt}_{3}$ (3 equiv.)

Scheme 1 Synthesis of compound 1d

where $A$ (or $A^{\prime}$ ) is the maximum intensity at wavelength $\lambda_{\max }$ and the parameters $a, b$ and $c$ are given by [17]

$c=\ln (\rho) / \sqrt{2 \ln (2)} \quad b=H \frac{\rho}{\rho^{2}-1} \exp \left(c^{2}\right) \quad a=H \frac{\rho}{\rho^{2}-1}$

where $H$ is the half-width of the band and $\rho$ is the skewness. The lognormal function sums account for the vibrational structure of compound spectrum. The components (1 and 2) have two different fitted anisotropy values, $r_{1}$ and $r_{2}$, given by

$r_{1}=\frac{A_{1 \mathrm{i}}-A_{1 \mathrm{i}}^{\prime}}{A_{1 \mathrm{i}}+2 A_{1 \mathrm{i}}^{\prime}}$ and $r_{2}=\frac{A_{2 \mathrm{i}}-A_{2 \mathrm{i}}^{\prime}}{A_{2 \mathrm{i}}+2 A_{2 \mathrm{i}}^{\prime}}$,

due to the additivity law of anisotropy [18],

$r=\sum_{\mathrm{i}} \frac{I_{\mathrm{i}}}{I_{\text {total }}} r_{\mathrm{i}}$

with

$r_{\mathrm{i}}=\frac{\left(I_{\mathrm{i}}\right)_{\mathrm{VV}}-G\left(I_{\mathrm{i}}\right)_{\mathrm{VH}}}{\left(I_{\mathrm{i}}\right)_{\mathrm{VV}}+2 G\left(I_{\mathrm{i}}\right)_{\mathrm{VH}}}$.

Therefore,

$A_{1 \mathrm{i}}^{\prime}=A_{1 \mathrm{i}}\left(\frac{1-r_{1}}{1+2 r_{1}}\right)$ and $A_{2 \mathrm{i}}^{\prime}=A_{2 \mathrm{i}}\left(\frac{1-r_{2}}{1+2 r_{2}}\right)$.

\section{Results and discussion}

\section{Synthesis of compound 1d}

As referred above, compound 1d was prepared in this work for comparison with compounds $\mathbf{1 a}-\mathbf{c}$ which were already prepared by some of us in a previous work [4], using the same method (Scheme 1).

Compound 1d was prepared in an excellent yield by a tandem one-pot $\mathrm{Pd} / \mathrm{Cu}$ catalyzed Sonogashira reaction of the 3-bromobenzo[ $b]$ thiophene-2-carboxylic acid with the 2-methoxyphenylacetylene followed by an intramolecular cyclization on the intermediate involving the carboxyl group and the triple bond [4].
Photophysical properties of compounds 1a-d in homogeneous solution

The absorption and fluorescence properties of compounds 1a, 1b, 1c and 1d were studied in several solvents. The maximum absorption $\left(\lambda_{\text {abs }}\right)$ and emission wavelengths $\left(\lambda_{\text {em }}\right)$, molar extinction coefficients $(\varepsilon)$ and fluorescence quantum yields $\left(\Phi_{\mathrm{F}}\right)$ of the four compounds are presented in Table 1. The normalized fluorescence spectra of compounds 1a-d are shown in Fig. 2. Examples of absorption spectra are displayed as insets.

The effect of solvent in the absorption spectrum of these compounds is generally small (insets of Fig. 2 and Table 1). Despite this, a red shift of the lowest energy absorption maximum can be observed with increasing solvent polarity, thus indicating that a $\pi \rightarrow \pi^{*}$ transition is involved. The molar extinction coefficients at absorption maxima are high $\left(\varepsilon>10^{4} \mathrm{M}^{-1} \mathrm{~cm}^{-1}\right)$, confirming this assumption.

In fluorescence spectra, significantly higher red shifts for all compounds can be observed from cyclohexane to more polar solvents, indicating that solvent relaxation after photoexcitation plays an important role. In polar solvents, a loss of vibrational structure is also detected (Fig. 2), more significant for compound $\mathbf{1 c}$, that presents completely nonstructured emission bands in the more polar environments. This behavior is usually related to an intramolecular charge transfer (ICT) mechanism and/or to specific solvent effects [15].

The red shifts in emission are larger for the compounds with the electron-donating (EDG) $\mathrm{OCH}_{3}$ group, especially for compound 1c (26 nm from cyclohexane to DMSO). Compounds 1a and $\mathbf{1 b}$ exhibit smaller red shifts, which may be due to the dual character of the $\mathrm{F}$ atom, which is an EDG by mesomeric effect $(+\mathrm{M})$ and an electron-withdrawing group (EWG) by inductive effect (-I). A similar behavior was already observed in tetracyclic lactams previously obtained by us, bearing this type of substituents [19].

The Lippert-Mataga plots (Eq. 3) for compounds 1a-d (Fig. 3) display a high linearity for all compounds in the solvents studied. Therefore, specific solute-solvent interactions like hydrogen bonding are not detectable by deviations of linearity in the Lippert-Mataga plots.

From $a b$ initio molecular quantum chemistry calculations, the cavity radius $(R)$ and the ground state dipole moment $\left(\mu_{\mathrm{g}}\right)$ were determined for the four compounds (Table 2), through an optimized structure provided by GAMESS software [21], using a RHF/3-21G(d) basis set [22] (Fig. 4). The optimized geometries show that molecules 1a and $\mathbf{1 c}$ are roughly planar, while in compounds $\mathbf{1 b}$ and $\mathbf{1 d}$ the fluorophenyl and the methoxyphenyl groups are out of the plane of the benzothienopyran-1-one moiety. The excited state dipole moments, $\mu_{\mathrm{e}}$, estimated from the Lippert-Mataga plots (Table 2), point to the presence of an intramolecular 
Table 1 Maximum absorption $\left(\lambda_{\text {abs }}\right)$ and emission wavelengths $\left(\lambda_{\mathrm{em}}\right)$, molar extinction coefficients $(\varepsilon)$ and fluorescence quantum yields $\left(\Phi_{\mathrm{F}}\right)$ for compounds $1 \mathrm{a}-\mathrm{d}$ in several solvents

\begin{tabular}{|c|c|c|c|c|c|c|c|c|c|c|c|c|}
\hline \multirow[t]{2}{*}{ Solvent } & \multicolumn{4}{|c|}{$\lambda_{\mathrm{abs}} / \mathrm{nm}\left(\varepsilon / 10^{4} \mathrm{M}^{-1} \mathrm{~cm}^{-1}\right)$} & \multicolumn{4}{|c|}{$\lambda_{\mathrm{em}} / \mathrm{nm}$} & \multicolumn{4}{|l|}{$\Phi_{\mathrm{F}}$} \\
\hline & 1a & $1 b$ & $1 \mathrm{c}$ & 1d & $1 \mathbf{a}$ & $1 b$ & $1 \mathrm{c}$ & 1d & $1 a^{a}$ & $1 b^{a}$ & $1 c^{b}$ & $1 d^{b}$ \\
\hline Cyclohexane & $\begin{array}{c}363(1.23) ; \\
275(2.03)\end{array}$ & $\begin{array}{c}361(1.57) ; \\
274(3.16)\end{array}$ & $\begin{array}{l}372(1.70) \\
283(2.88)\end{array}$ & $\begin{array}{l}366(1.36) ; \\
274(2.57)\end{array}$ & 418 & 409 & 433 & 422 & 0.002 & 0.005 & 0.006 & 0.009 \\
\hline Dioxane & $\begin{array}{c}365(1.25) ; \\
277(2.67)\end{array}$ & $\begin{array}{c}365(2.17) ; \\
277(4.12)\end{array}$ & $\begin{array}{l}374(1.89) \\
266(3.03)\end{array}$ & $\begin{array}{l}367 \text { (1.66); } \\
276(2.09)\end{array}$ & 422 & 415 & 440 & 426 & 0.006 & 0.013 & 0.020 & 0.016 \\
\hline Dichloromethane & $\begin{array}{c}366(1.72) \\
277(3.78)\end{array}$ & $\begin{array}{c}363(1.46) ; \\
276(3.39)\end{array}$ & $\begin{array}{c}376(1.40) \\
285(2.75)\end{array}$ & $\begin{array}{c}371(1.30) ; \\
275(2.48)\end{array}$ & 425 & 417 & 449 & 434 & 0.005 & 0.014 & 0.022 & 0.020 \\
\hline Dimethylformamide & $367(1.36)^{\mathrm{c}}$ & $363(1.40)^{\mathrm{c}}$ & $\begin{array}{c}378(2.06) ; \\
286(2.75)\end{array}$ & $\begin{array}{c}370(1.82) ; \\
278(1.73)\end{array}$ & 427 & 419 & 456 & 437 & 0.010 & 0.012 & 0.039 & 0.01 \\
\hline Dimethylsulfoxide & $369(1.50)^{\mathrm{c}}$ & $363(1.70)^{\mathrm{c}}$ & $\begin{array}{c}381(2.29) \\
286(2.93)\end{array}$ & $\begin{array}{c}372(1.51) ; \\
279(1.61)\end{array}$ & 429 & 420 & 459 & 438 & 0.012 & 0.016 & 0.068 & 0.030 \\
\hline Acetonitrilo & $\begin{array}{c}366(1.04) ; \\
276(2.06)\end{array}$ & $\begin{array}{c}360(1.29) ; \\
276(3.39)\end{array}$ & $\begin{array}{l}373(1.23) ; \\
282(2.61)\end{array}$ & $\begin{array}{l}367(1.71) ; \\
284(3.41)\end{array}$ & 425 & 416 & 452 & 433 & 0.004 & 0.008 & 0.021 & 0.012 \\
\hline Ethanol & $\begin{array}{c}366(1.57) ; \\
277(3.67)\end{array}$ & $\begin{array}{c}362(1.30) ; \\
275(2.94)\end{array}$ & $\begin{array}{c}377(1.77) ; \\
284(3.63)\end{array}$ & $\begin{array}{c}370(1.49) ; \\
276(2.90)\end{array}$ & 426 & 418 & 456 & 435 & 0.007 & 0.012 & 0.040 & 0.022 \\
\hline Methanol & $\begin{array}{c}367(1.58) \\
277(3.69)\end{array}$ & $\begin{array}{c}363(1.09) ; \\
275(2.58)\end{array}$ & $\begin{array}{c}377(1.43) ; \\
283(2.69)\end{array}$ & $\begin{array}{c}370(1.51) ; \\
275(3.27)\end{array}$ & 427 & 420 & 458 & 437 & 0.006 & 0.012 & 0.047 & 0.023 \\
\hline
\end{tabular}

${ }^{\text {a }}$ Relative to anthracene in ethanol $\left(\Phi_{\mathrm{r}}=0.27\right.$ [12])

${ }^{\mathrm{b}}$ Relative to quinine sulfate in $0.05 \mathrm{M} \mathrm{H}_{2} \mathrm{SO}_{4}\left(\Phi_{\mathrm{r}}=0.546[13,14]\right)$

${ }^{\mathrm{c}}$ Solvent cut-offs: Dimethylformamide: $275 \mathrm{~nm}$; Dimethylsulfoxide: $270 \mathrm{~nm}$

charge transfer (ICT) mechanism, especially for compound 1c. Twisted intramolecular charge transfer states (TICT) usually exhibit higher excited state dipole moments $(\geq 20 \mathrm{D})$ [23] than those here obtained.

Figure 5 reports the representation of HOMO and LUMO molecular orbitals for the four compounds. In all compounds, the HOMO-LUMO transition causes an increase in the electronic density of the $\mathrm{O}$ atom of the pyranone ring, especially in the case of compound 1c. It can be observed that the HOMO-LUMO transition of compound 1c exhibits a charge transfer from the oxygen atom of the methoxyphenyl group to the aromatic ring system,

Fig. 2 Normalized fluorescence (at peak of maximum emission) spectra of compounds 1a-d in several solvents: cyclohexane $(---)$; dioxane $(\cdots \cdots)$; dichloromethane (-); dimethylformamide (.......); dimethylsulfoxide $(-\cdots-)$; acetonitrile (- - - -); ethanol $(-\cdot-\cdot-)$; methanol $(-\cdot-\cdot-\cdot-)$. Insets: Absorption spectra of solutions of compounds $\mathbf{1 a - d}$ in dichloromethane and in ethanol, as examples. A Compound 1a $\left(7 \times 10^{-6} \mathrm{M}\right.$ solutions for fluorescence, $\lambda_{\mathrm{exc}}=360 \mathrm{~nm}$, and $2.4 \times$ $10^{-5} \mathrm{M}$ for absorption); B Compound $1 \mathbf{b}\left(4 \times 10^{-6} \mathrm{M}\right.$ solutions for fluorescence, $\lambda_{\text {exc }}=360 \mathrm{~nm}$, and $2.5 \times 10^{-5} \mathrm{M}$ for absorption); $\mathbf{C}$ Compound $\mathbf{1 c}$ $\left(4 \times 10^{-6} \mathrm{M}\right.$ solutions for fluorescence, $\lambda_{\mathrm{exc}}=370 \mathrm{~nm}$, and $2 \times$ $10^{-5} \mathrm{M}$ for absorption); D Compound $1 \mathrm{~d}\left(4 \times 10^{-6} \mathrm{M}\right.$ solutions for fluorescence, $\lambda_{\text {exc }}=370 \mathrm{~nm}$, and $2 \times 10^{-5} \mathrm{M}$ for absorption)
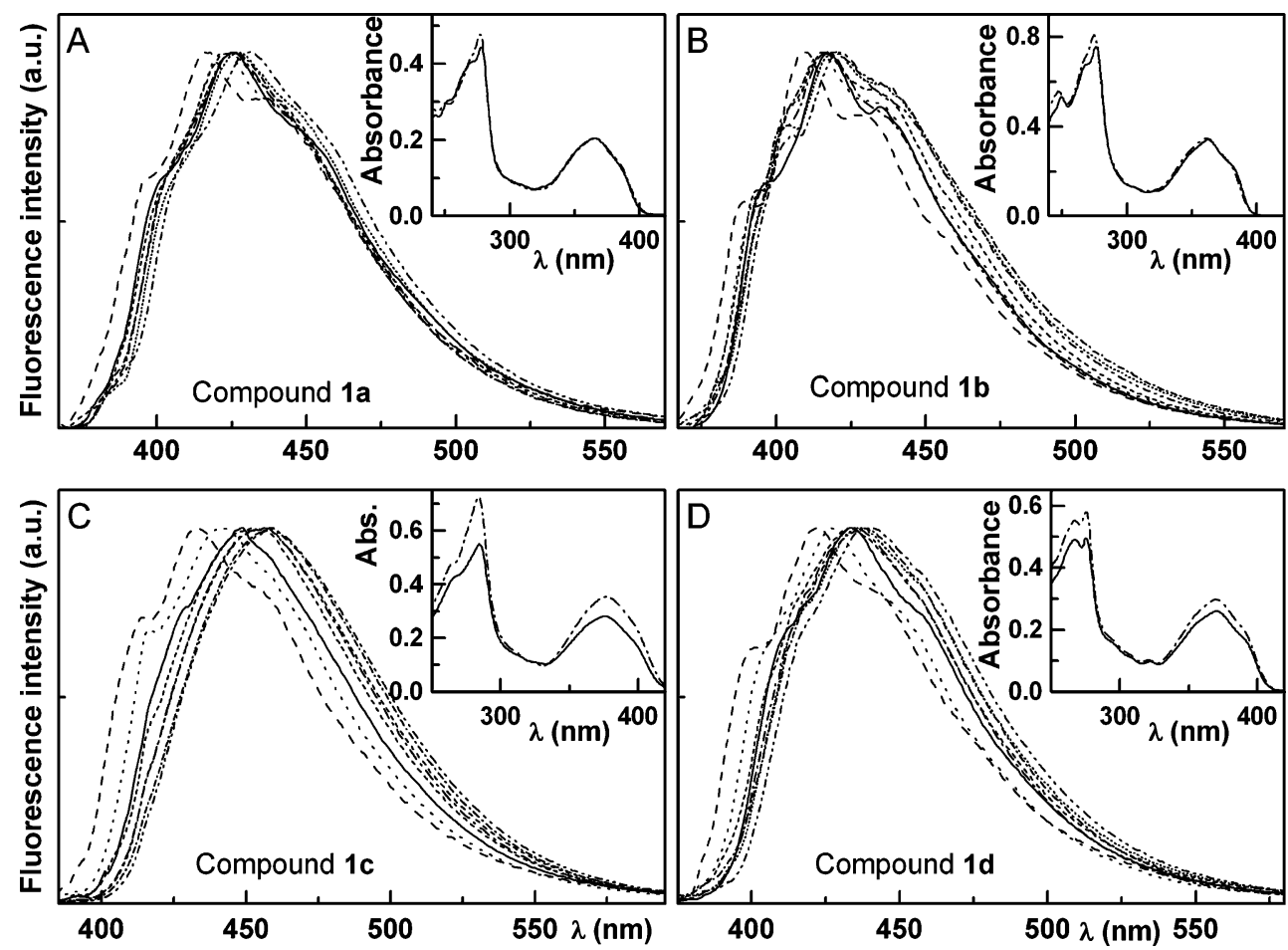
Fig. 3 Lippert-Mataga plots for compounds $1 \mathrm{a}, \mathbf{1 b}, \mathbf{1 c}$ and $1 \mathrm{~d}$.

$A$ : cyclohexane; $B$ : dioxane;

$C$ : dichloromethane;

$D$ : dimethylsulfoxide;

$E$ : dimethylformamide;

$F$ : ethanol; $G$ : acetonitrile;

$H$ : methanol (values of $\varepsilon$ and $n$ were obtained from ref. [20])

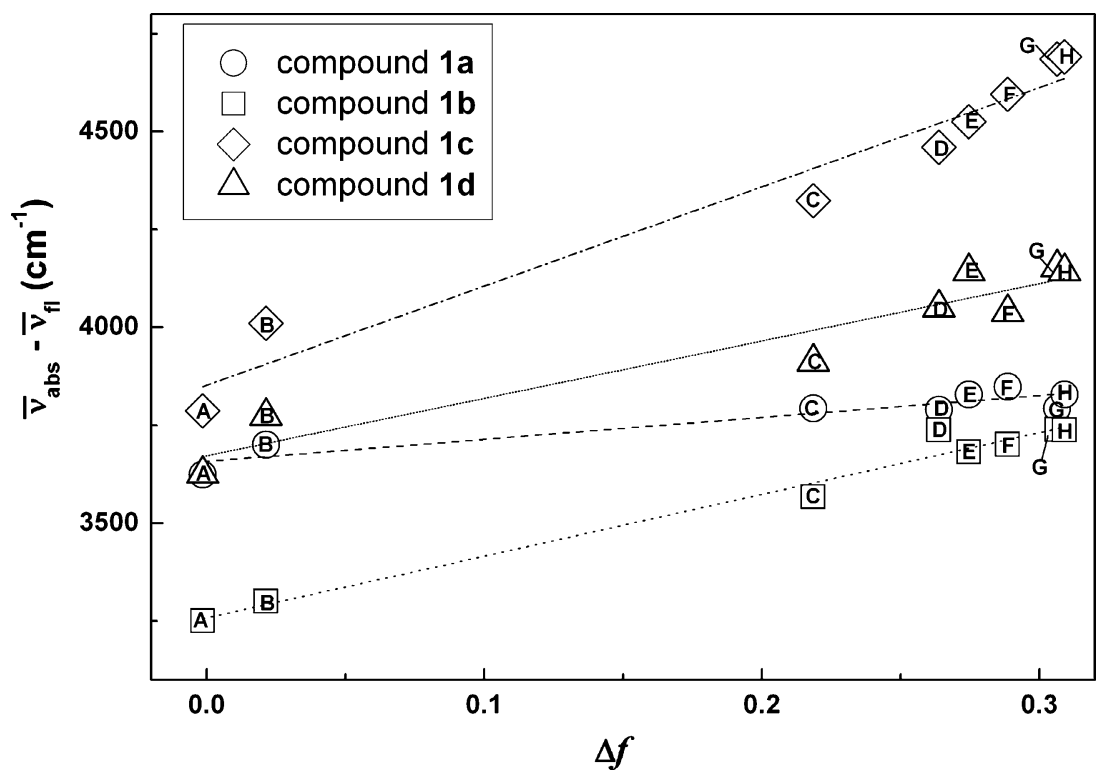

confirming the ICT character of the excited state. The effect is significantly lower for compound 1d. Comparing compounds 1a and $\mathbf{1 b}$, the $\mathrm{F}$ atom presents higher electronic density in compound 1a, which decreases slightly upon HOMO-LUMO transition. It can also be observed that the carbon atom bound to fluorine decreases its electronic density upon HOMO-LUMO transition in compound 1a, the opposite occurring in compound $\mathbf{1 b}$.

All compounds 1a-d present low fluorescence quantum yields in all solvents $\left(\Phi_{\mathrm{F}} \leq 6.8 \%\right.$, Table 1). Fluorescence quantum yields are very low $\left(\Phi_{\mathrm{F}}<2 \%\right)$ for compounds with a $\mathrm{F}$ substituent (1a and 1b). For compounds with a
Table 2 Cavity radius $(R)$ and ground state dipole moments $\left(\mu_{\mathrm{g}}\right)$, obtained from theoretical calculations, and excited state dipole moments $\left(\mu_{\mathrm{e}}\right)$ calculated from the Lippert-Mataga plots

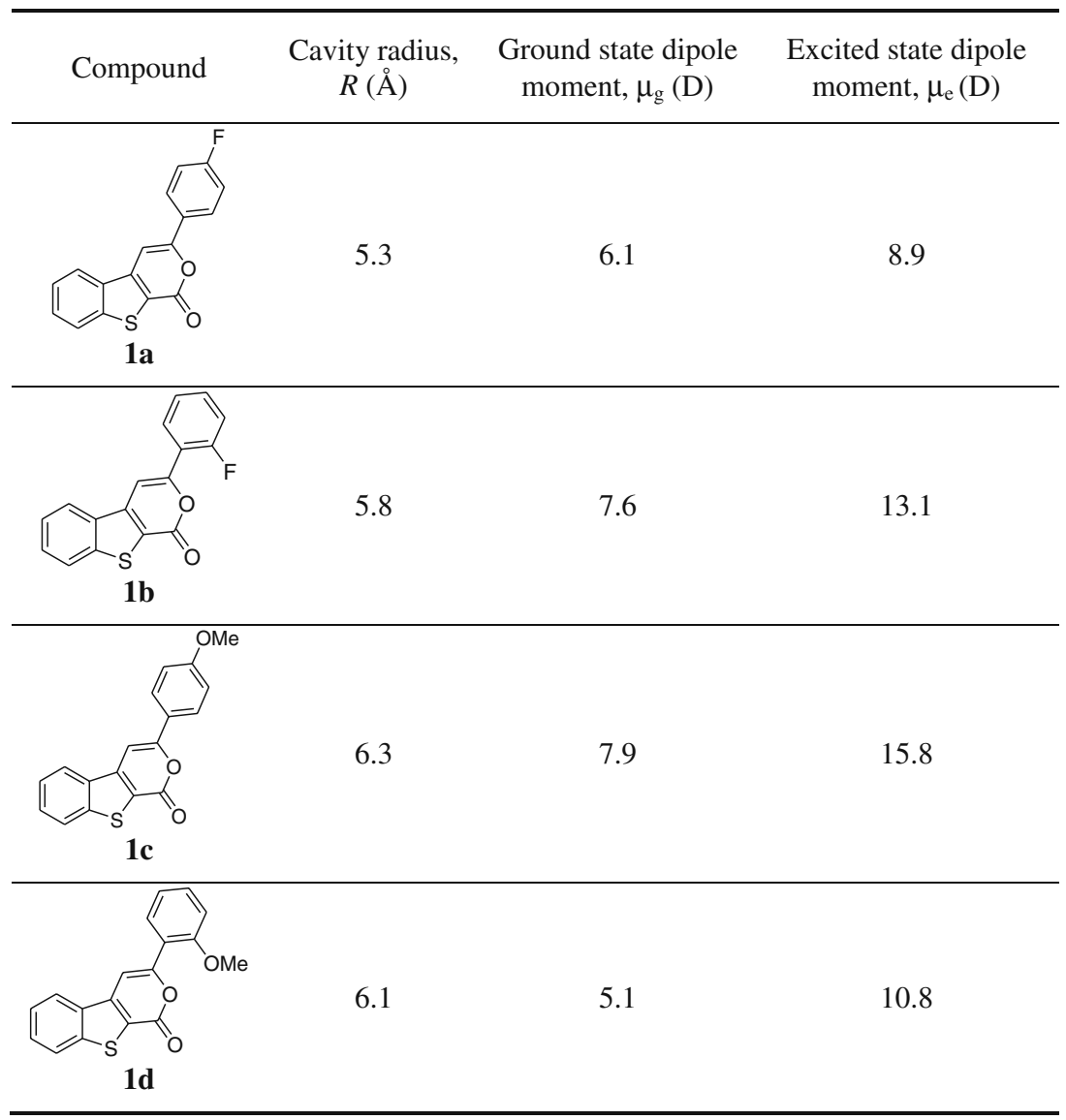



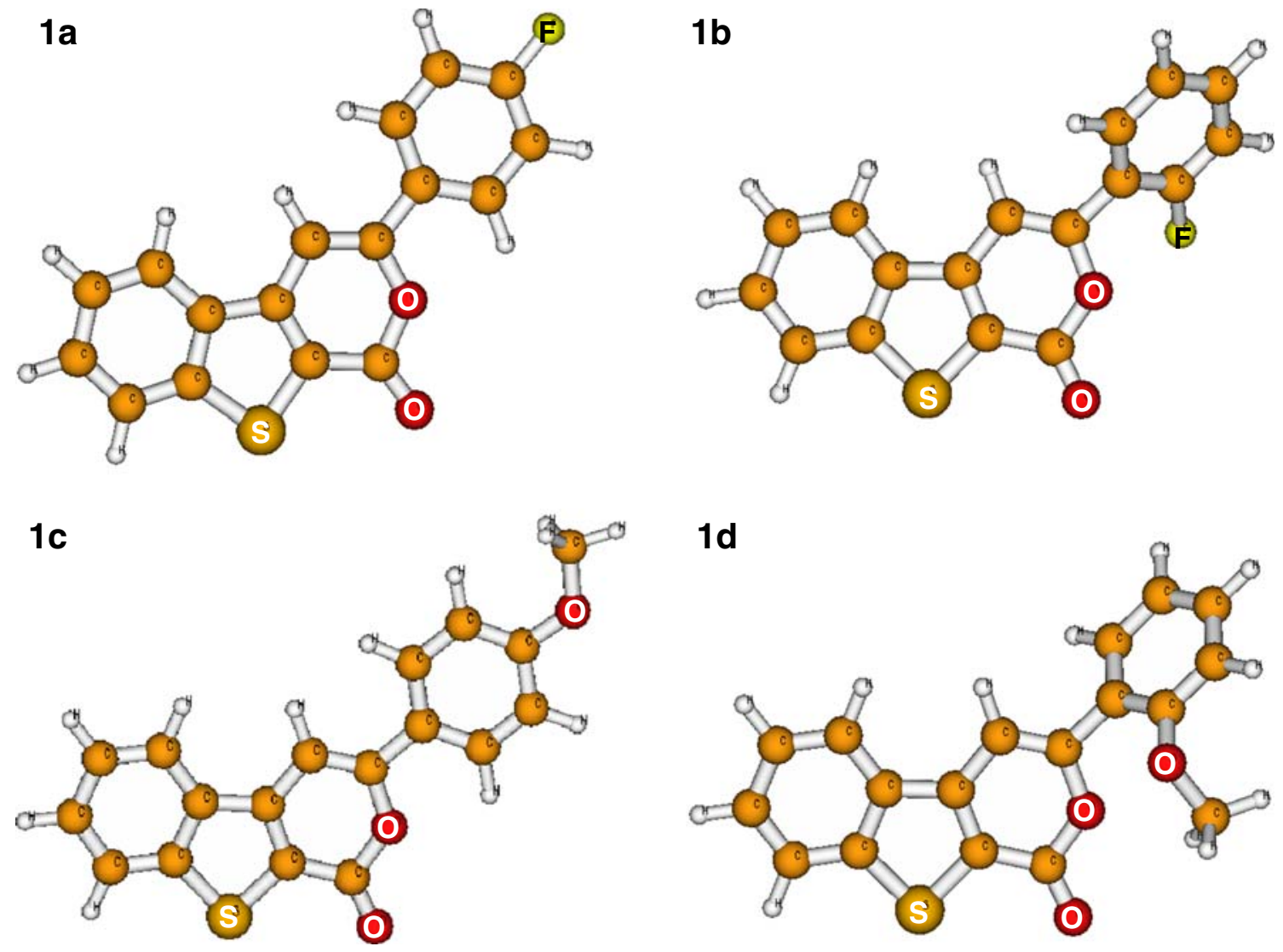

Fig. 4 Optimized structures of compounds $\mathbf{1 a}, \mathbf{1 b}, \mathbf{1}$ and $\mathbf{1 d}$ (obtained by GAMESS software), with the indication of $\mathrm{S}, \mathrm{O}$ and $\mathrm{F}$ atoms

methoxy substituent (1c and $\mathbf{1 d}), \Phi_{\mathrm{F}}$ values are generally higher, especially in polar solvents. The low values of fluorescence quantum yield observed for these compounds are due to the presence of the $\mathrm{S}$ atom in the thiophene ring, which may promote the intersystem crossing process by enhancement of spin-orbit coupling interaction [15, 24], as observed for other molecules which include a thiophene ring $[1,19]$. The expected formation of hydrogen bonds of compounds 1a-d with protic solvents was not inferred from deviations of the Lippert-Mataga plots (Fig. 3) and, if they occur, do not influence the $\Phi_{\mathrm{F}}$ values in alcohols (Table 1).

Interaction of compounds 1a-d with lipid membranes

Due to their promising antitumoral activity [4], photophysical studies of compounds 1a-d incorporated in lipid vesicles were also performed. These experiments are important to evaluate their location in liposomes pointing to drug delivery applications.

Different types of lipid molecules, Egg-PC, DPPC and DODAB, were used for the vesicles preparation. Egg-PC is a natural phospholipid mixture, where all molecules have the same polar head group (phosphatidylcholine) but several hydrocarbon chains, differing in length and degree of unsaturation. Egg-PC main components are 16:0 PC, 18:0 PC and 18:1 PC [25]. Considering DPPC (16:0 PC) and DODAB, it is known that at room temperature, both lipids are in the ordered gel phase, where the hydrocarbon chains are fully extended and closely packed. Above the melting transition temperature, $41{ }^{\circ} \mathrm{C}$ for DPPC [8] and $45{ }^{\circ} \mathrm{C}$ for DODAB [9], these lipids attains the disordered liquid-crystalline phase.

The emission spectra of compounds 1a-d in lipid membranes are displayed in Fig. 6. Compound 1a (Fig. 6A) exhibits a composed spectrum in lipids at the gel phase (DODAB and DPPC at $25^{\circ} \mathrm{C}$ ), showing the existence of two emission bands (with maxima near $420 \mathrm{~nm}$ and $438 \mathrm{~nm}$, Table 3), pointing to the existence of two different locations of 1a molecules in these rigid lipid membranes. At the liquidcrystalline phase (both DPPC and DODAB at $55^{\circ} \mathrm{C}$ and Egg-PC at $25^{\circ} \mathrm{C}$ ), only one emission band is observed, with very slight differences between the three lipids. The maximum emission wavelengths in this fluid phase (Table 3) are similar to the lower energy maximum of the compound in lipids at the gel phase. A distinct behavior is observed for compound $\mathbf{1 b}$, where the position and shape of the emission bands are similar in all lipids either at $25{ }^{\circ} \mathrm{C}$ or at $55^{\circ} \mathrm{C}$. A decrease of the shoulder at the higher energy region is 
Fig. 5 Representation of HOMO (lower) and LUMO (upper) molecular orbitals of compounds 1a-d
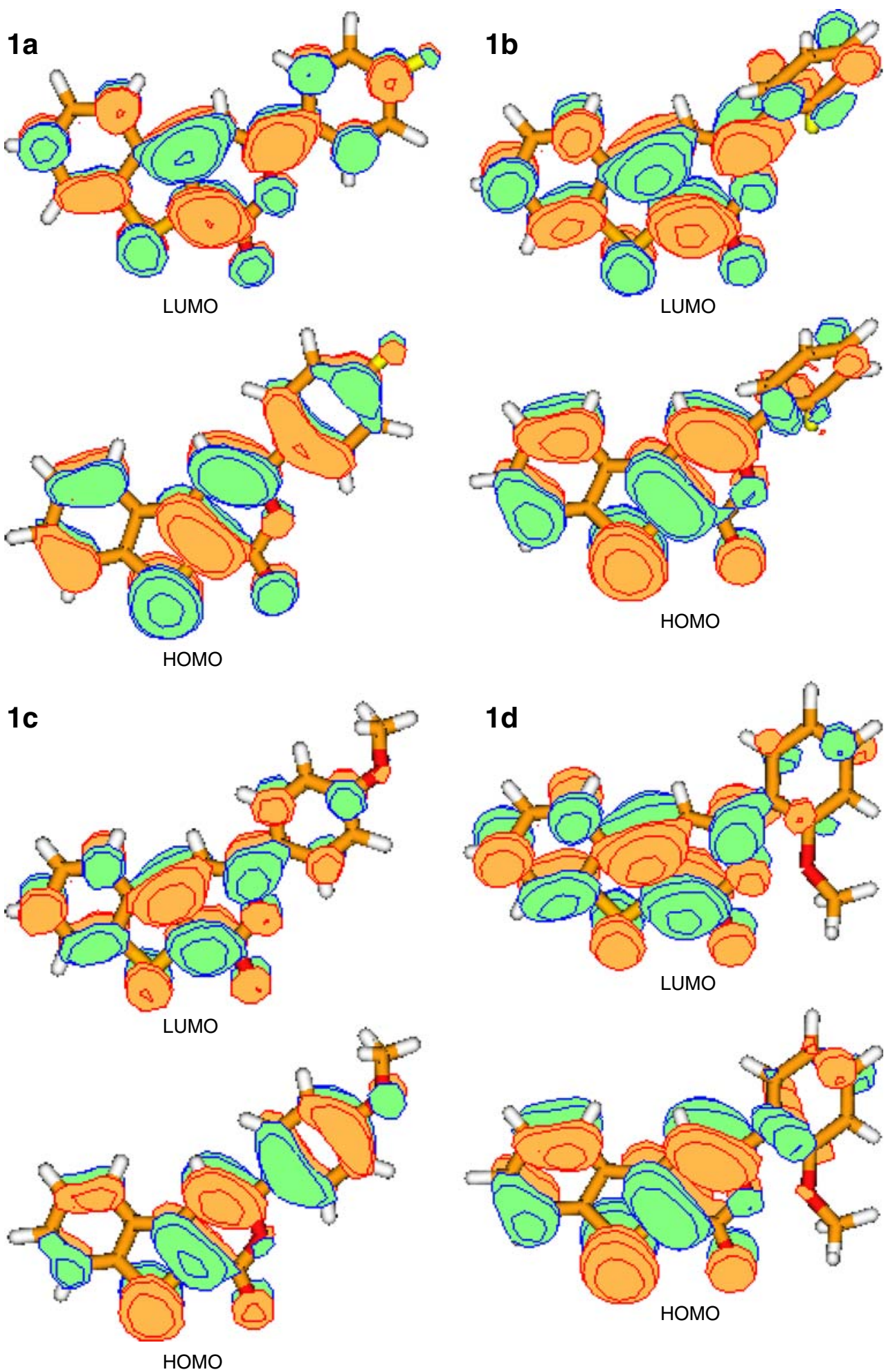

observed in DODAB, especially in the fluid phase (Fig. 6B). The maximum emission wavelengths indicate an environment of moderate polarity, similar to dioxane and acetonitrile (Tables 1 and 3). In homogeneous solution, the effect of the temperature increase in the fluorescence of these compounds is a $c a .40 \%$ reduction and a very small blue shift $(1-2 \mathrm{~nm})$ between $25{ }^{\circ} \mathrm{C}$ and $55^{\circ} \mathrm{C}$.
For compounds 1c and 1d (Fig. 6C and D, respectively) a structured emission is observed in Egg-PC, especially for compound 1d. In DPPC and DODAB, the emission bands of both compounds are basically non-structured and, in some cases, seem clearly to be composed of two emissions. For compound 1c, a significant spectral shift is observed between the different lipid membranes. The maximum 
Fig. 6 Normalized fluorescence spectra of compounds 1a-d in lipid membranes: Egg-PC at $25{ }^{\circ} \mathrm{C}(-)$; DPPC gel phase at $25{ }^{\circ} \mathrm{C}(---)$; DPPC liquidcrystalline phase at $55^{\circ} \mathrm{C}$ $(-\cdot-\cdot-)$; DODAB gel phase at $25{ }^{\circ} \mathrm{C}(\cdots \cdots)$; DODAB liquid-crystalline phase at $55^{\circ} \mathrm{C}$ (........). Insets: Fluorescence anisotropy spectrum of compounds 1a-d in DPPC at gel phase $\left(25^{\circ} \mathrm{C}\right)$, as an example.

A Compound 1a $\left(\lambda_{\text {exc }}=\right.$ $360 \mathrm{~nm}) ; \mathbf{B}$ Compound $\mathbf{1 b}$ $\left(\lambda_{\text {exc }}=360 \mathrm{~nm}\right)$; C Compound $1 c\left(\lambda_{\text {exc }}=370 \mathrm{~nm}\right) ; \mathbf{D}$ Compound 1d $\left(\lambda_{\mathrm{exc}}=370 \mathrm{~nm}\right)$
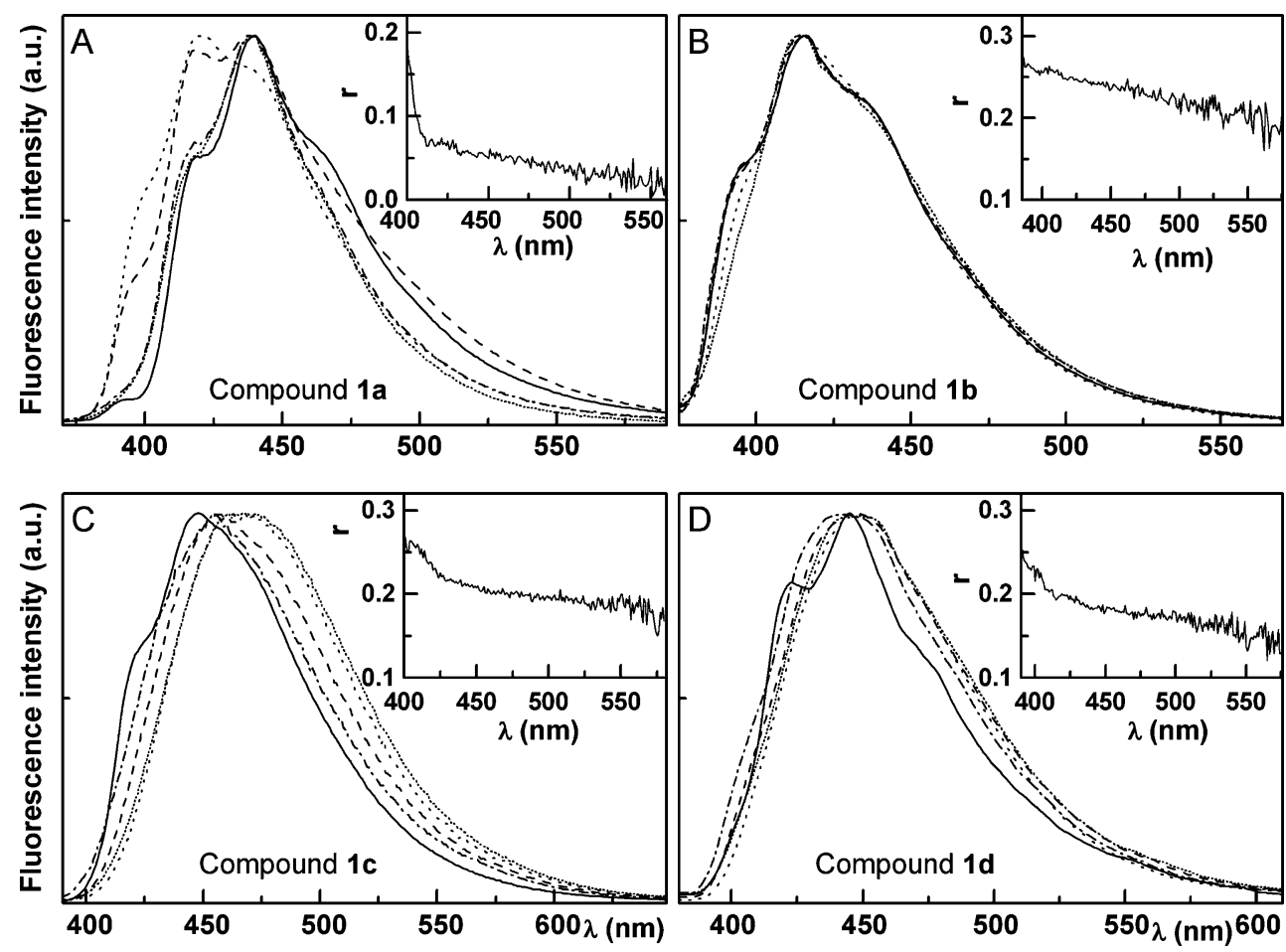

emission wavelength in Egg-PC is similar to that in dichloromethane, while for DODAB a more hydrated environment is predicted. For compound 1d, the emission maxima in all lipids are similar to the observed in ethylene glycol, pointing also to a hydrated location of this compound in lipid vesicles.

In order to obtain further information about the behavior of these molecules in lipid membranes, fluorescence (steady-state) anisotropy measurements were performed. The average fluorescence steady-state anisotropies $(\bar{r})$ and fluorescence quantum yields of the four compounds in lipid vesicles are shown in Table 3. Fluorescence anisotropy values in ethylene glycol at room temperature were also determined for comparison, being similar for all molecules. For each compound, an example of fluorescence anisotropy spectrum is displayed as inset in Fig. 6. Notable variations with emission wavelength are observed for compound 1a (inset of Fig. 6A), while the variations are smaller for compounds 1c, $1 \mathbf{d}$ and $\mathbf{1 b}$ (inset of Fig. 6B-D). In ethylene glycol, the steady-state fluorescence anisotropy is constant with wavelength for all compounds. The behavior observed in lipid membranes points to the existence of two emitting species, corresponding to compound locations in different environments.

Figures 7 and 8 display an example of the fit of anisotropy components, $I_{\mathrm{VV}}$ and $\mathrm{G} \cdot I_{\mathrm{VH}}$ (Eqs. 5 and 6), and the fitting to the anisotropy curve, as well as the respective spectral contributions recovered from the fitting. The results are given in Table 4.

For all compounds, two components were recovered, one with higher anisotropy $\left(r_{1}\right)$ and lower maximum

Table 3 Average steady-state fluorescence anisotropy $(\bar{r})$ values, fluorescence quantum yields and maximum emission wavelengths $\left(\lambda_{\text {em }}\right)$ of compounds 1a-d in lipid membranes. Values in ethylene glycol at room temperature are also shown for comparison

\begin{tabular}{|c|c|c|c|c|c|c|c|c|c|c|c|c|}
\hline & \multicolumn{3}{|c|}{ Compound 1a } & \multicolumn{3}{|c|}{ Compound $\mathbf{1 b}$} & \multicolumn{3}{|c|}{ Compound 1c } & \multicolumn{3}{|c|}{ Compound 1d } \\
\hline & $\lambda_{\mathrm{em}} / \mathrm{nm}$ & $\Phi_{\mathrm{F}}{ }^{\mathrm{a}}$ & $\bar{r}$ & $\lambda_{\mathrm{em}} / \mathrm{nm}$ & $\Phi_{\mathrm{F}}{ }^{\mathrm{a}}$ & $\bar{r}$ & $\lambda_{\mathrm{em}} / \mathrm{nm}$ & $\Phi_{\mathrm{F}}^{\mathrm{b}}$ & $\bar{r}$ & $\lambda_{\mathrm{em}} / \mathrm{nm}$ & $\Phi_{\mathrm{F}}^{\mathrm{b}}$ & $\bar{r}$ \\
\hline DPPC $\left(25{ }^{\circ} \mathrm{C}\right)$ & $419 ; 438$ & 0.034 & 0.089 & 416 & 0.011 & 0.234 & 459 & 0.042 & 0.203 & 448 & 0.030 & 0.194 \\
\hline DPPC $\left(55^{\circ} \mathrm{C}\right)$ & 438 & 0.013 & 0.065 & 415 & 0.004 & 0.185 & 457 & 0.010 & 0.192 & 444 & 0.008 & 0.190 \\
\hline $\operatorname{DODAB}\left(25{ }^{\circ} \mathrm{C}\right)$ & 421 & 0.084 & 0.188 & 415 & 0.013 & 0.210 & 467 & 0.054 & 0.173 & 449 & 0.031 & 0.189 \\
\hline $\operatorname{DODAB}\left(55{ }^{\circ} \mathrm{C}\right)$ & 439 & 0.047 & 0.075 & 414 & 0.005 & 0.140 & 469 & 0.017 & 0.161 & 448 & 0.011 & 0.167 \\
\hline Egg-PC $\left(25{ }^{\circ} \mathrm{C}\right)$ & 440 & 0.024 & 0.066 & 416 & 0.006 & 0.231 & 449 & 0.022 & 0.229 & $424 ; 445$ & 0.015 & 0.212 \\
\hline Ethylene glycol $\left(25{ }^{\circ} \mathrm{C}\right)$ & 431 & - & 0.276 & 421 & - & 0.272 & 465 & - & 0.240 & 444 & - & 0.264 \\
\hline
\end{tabular}

${ }^{\mathrm{a}}$ Relative to anthracene in ethanol $\left(\Phi_{\mathrm{r}}=0.27\right.$ at $\left.25{ }^{\circ} \mathrm{C}[12]\right)$

${ }^{\mathrm{b}}$ Relative to quinine sulfate in $0.05 \mathrm{M} \mathrm{H}_{2} \mathrm{SO}_{4}\left(\Phi_{\mathrm{r}}=0.546\right.$ at $\left.25^{\circ} \mathrm{C}[13,14]\right)$ 
Fig. 7 Fit of compound 1a in DODAB gel phase $\left(25^{\circ} \mathrm{C}\right)$. A $I_{\mathrm{VV}}$ component and fitted curve; B $G \cdot I_{\mathrm{VH}}$ component and fitted curve; C Recovered spectral components from the fitting procedure; D Fluorescence steady-state anisotropy and recovered curve (calculated from the recovered components)
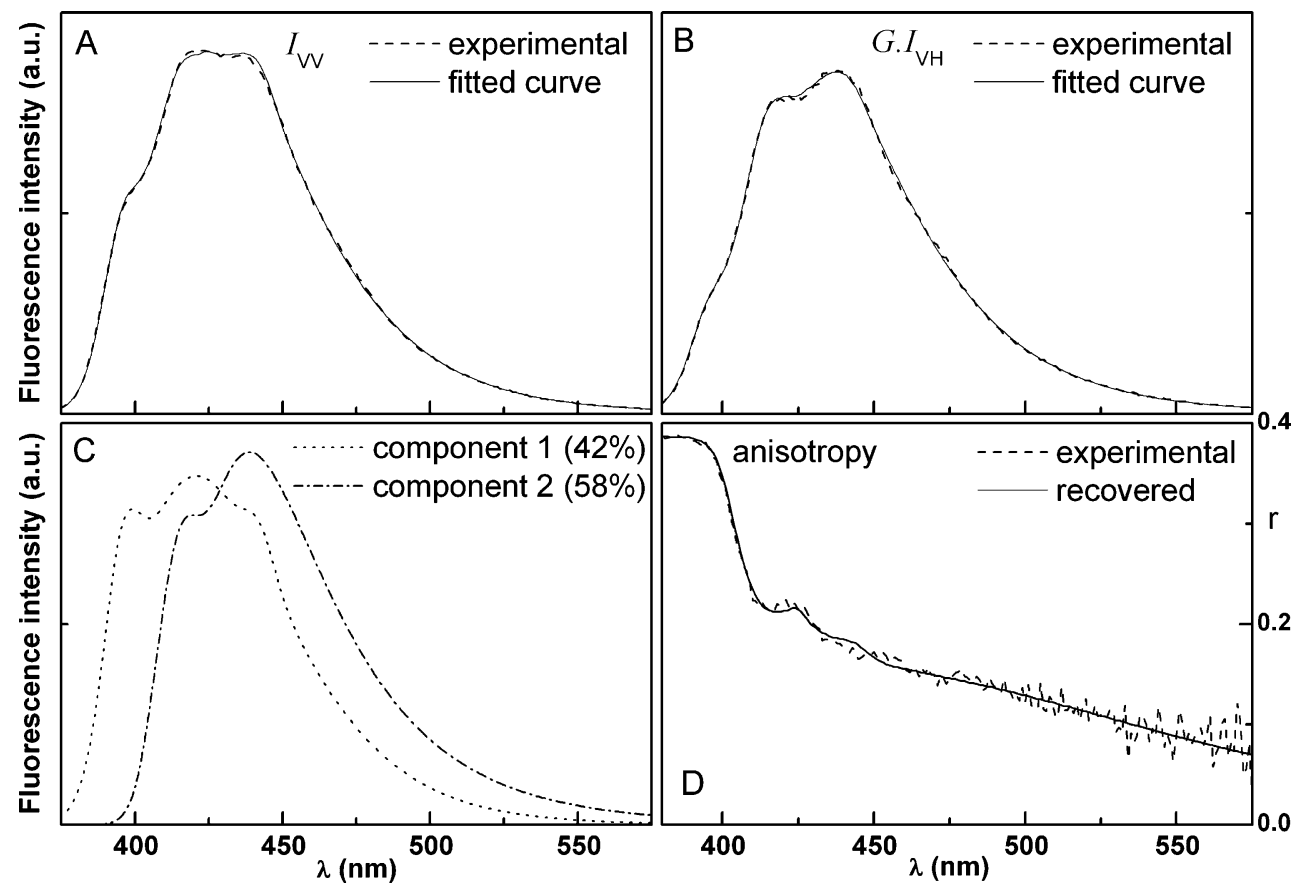

emission wavelength $\left(\lambda_{1}\right)$, corresponding to compound molecules located deeper in the lipid membrane, and another corresponding to a more hydrated environment (higher emission wavelength, $\lambda_{2}$, and lower anisotropy, $r_{2}$ ). The fraction of the first component, $f_{1}$ (corresponding to the fraction of spectral area), is also presented. In general, the microviscosity decreases from the interface to the interior of the membrane [26, 27], with a more pronounced variation when the membrane is in the liquid-crystalline phase [27]. Thus, the recovered anisotropy values for the two compound locations are in opposite direction to that given by the spectral band positions. This can be explained by the observed increase in the fluorescence quantum yield with solvent polarity (Table 1). The absorption spectra exhibit a very low dependence on solvent polarity (insets of Fig. 2). From the Strickler-Berg relation [18, 28], it can be concluded that the radiative lifetime, $\tau_{r}$, is mainly invariant with polarity. Therefore, a higher $\Phi_{\mathrm{F}}$ value results from an increase of the excited-state lifetime. This, in turn, contributes to a decrease in fluorescence anisotropy, as the excited
Fig. 8 Fit of compound 1d in DODAB gel phase $\left(25^{\circ} \mathrm{C}\right)$. A $I_{\mathrm{VV}}$ component and fitted curve; B $G \cdot I_{\mathrm{VH}}$ component and fitted curve; C Recovered spectral components from the fitting procedure; D Fluorescence steady-state anisotropy and recovered curve (calculated from the recovered components)

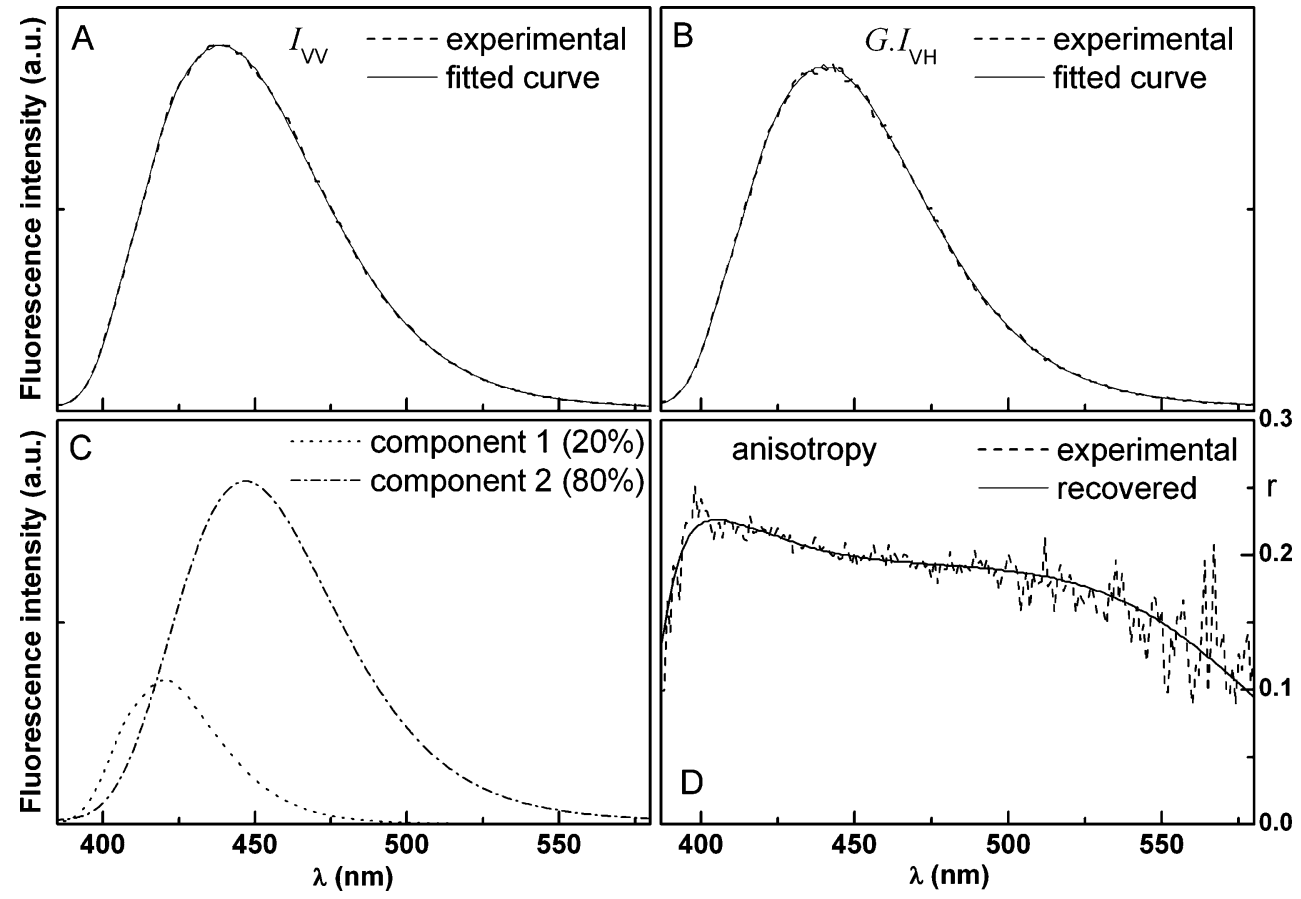


compound has more time to rotate leading to a depolarization of its fluorescence.

Compound 1a locates mainly in a very hydrated environment $\left(\lambda_{2}\right.$ values higher than $\lambda_{\max }$ observed in methanol), while compound $\mathbf{1 b}$ preferential location is deeper inside the lipid membrane, as the component with lower maximum emission wavelength $(406-414 \mathrm{~nm})$ is dominant $\left(f_{1}>0.50\right)$. For compounds $\mathbf{1 a}$ and $\mathbf{1 b}$, similar environments (as inferred from the maximum emission wavelengths) show very distinct anisotropy values for component 2 (Table 4), $r_{2}$ value being especially low for compound 1a. The different geometry ( $v d$. Fig. 4 ) of both compounds cannot explain this distinct behavior, as compounds 1c and 1d which have also different geometries do not show similar variations in anisotropy values. This peculiar behavior of compound 1a indicates that some of its molecules locate at the outer part of the liposome interface, with a fluidity approaching that of water.

Upon transition from the gel $\left(25^{\circ} \mathrm{C}\right)$ to the liquidcrystalline $\left(55^{\circ} \mathrm{C}\right)$ phase (for DPPC and DODAB), compound 1a relocates to a more hydrated environment, as the $f_{1}$ value strongly decreases. The opposite seems to happen for compound $1 \mathrm{c}$, where $f_{1}$ clearly increases at $55^{\circ} \mathrm{C}$. Therefore, compounds with a planar geometry (1a and 1c) have higher mobility in the lipid vesicles when phase transition occurs.

Liposomes have been widely used to deliver anticancer agents, in order to reduce the toxic effects of the drugs or to increase the drug circulation time and effectiveness [29]. The studies described here are important for the incorporation of the new potential antitumoral benzothienopyran-1-ones in liposomes for future controlled drug delivery applications.

\section{Conclusions}

The four new potential antitumoral compounds, 3arylbenzothieno[2,3-c]pyran-1-ones, show a solvent sensitive emission, with significant red shifts in polar solvents for the methoxylated compounds. Compound 1c exhibits the higher fluorescence quantum yields in all solvents studied. The estimated excited state dipole moments point to an ICT character of the excited state, more pronounced for compound 1c, confirmed by molecular quantum chemistry calculations.

Photophysical studies of the compounds incorporated in liposomes of DPPC, DODAB and Egg-PC indicate that all the compounds exhibit two different locations, one due to a deep penetration in the lipid membrane and other corresponding to a more hydrated environment. Compounds with a planar geometry (1a and 1c) have higher mobility in the lipid vesicles when phase transition occurs.

Considering the already tested anti-proliferative activity of human tumor cell lines exhibited by these molecules, the 
results obtained here are important for future drug delivery applications using liposomes.

Acknowledgements Foundation for the Science and Technology (FCT) - Portugal and FEDER (Fundo Europeu de Desenvolvimento Regional), for financial support through Centro de Física (CFUM) and Centro de Química (CQ-UM) of University of Minho and through the Project PTDC/QUI/81238/2006. M.S.D. Carvalho and R.C. Calhelha acknowledge FCT for their $\mathrm{PhD}$ grants SFRH/BD/47052/2008 and SFRH/BD/29274/2006, respectively.

\section{References}

1. Queiroz M-JRP, Castanheira EMS, Pinto AMR, Ferreira ICFR, Begouin A, Kirsch G (2006) Synthesis of the first thieno- $\delta$ carboline. Fluorescence studies in solution and in lipid vesicles. J Photochem Photobiol A: Chem 181:290-296

2. Castanheira EMS, Abreu AS, Carvalho MSD, Queiroz M-JRP, Ferreira PMT (2009) Fluorescence studies on potential antitumoral heteroaryl and heteroannulated indoles in solution and in lipid membranes. J Fluorescence 19:501-509

3. Castanheira EMS, Abreu AS, Queiroz M-JRP, Ferreira PMT, Coutinho PJG, Nazareth N, Nascimento MS-J (2009) Fluorescence properties of a potential antitumoral benzothieno[3, 2-b]pyrole in solution and lipid membranes. J Photochem Photobiol A: Chem 206:220-226

4. Queiroz M-JRP, Calhelha RC, Vale-Silva LA, Pinto E, Nascimento MS-J (2009) Synthesis of novel 3-(aryl)benzothieno[2, 3-c]pyran-1ones from Sonogashira products and intramolecular cyclization: antitumoral activity evaluation. Eur J Med Chem 44:1893-1899

5. Lasic DD (1995) In: Lasic DD, Barenholz Y (eds) Handbook of nonmedical applications of liposomes: from gene delivery and diagnostic to ecology, vol IV. CRC, New York, pp 1-32

6. Lasic DD, Ruff D (1998) In: Lasic DD, Papahadjoupoulos D (eds) Medical applications of liposomes. Elsevier, Netherlands, pp 353-394

7. Pedroso de Lima MC, Simões S, Pires P, Faneca H, Düzgünes N (2001) Cationic lipid-DNA complexes in gene delivery: from biophysics to biological applications. Adv Drug Deliv Rev 47:277-294

8. Lentz BR (1989) Membrane "fluidity" as detected by diphenylhexatriene probes. Chem Phys Lipids 50:171-190

9. Feitosa E, Barreleiro PCA, Olofsson G (2000) Phase transition in dioctadecyldimethylammonium bromide and chloride vesicles prepared by different methods. Chem Phys Lipids 105:201-213

10. Demas JN, Crosby GA (1971) The measurement of photoluminescence quantum yields. A review. J Phys Chem 75:991-1024

11. Fery-Forgues S, Lavabre D (1999) Are fluorescence quantum yields so tricky to measure? A demonstration using familiar stationery products. J Chem Educ 76:1260-1264
12. Dawson WR, Windsor MW (1968) Fluorescence yields of aromatic compounds. J Phys Chem 72:3251-3260

13. Melhuish WH (1961) Quantum efficiencies of fluorescence of organic substances - effect of solvent and concentration of fluorescent solute. J Phys Chem 65:229-235

14. Meech SR, Phillips D (1983) Photophysics of some common fluorescence standards. J Photochem 23:193-217

15. Lakowicz JR (1999) Principles of fluorescence spectroscopy. Kluwer Academic/Plenum, New York

16. Mataga N, Kubota T (1970) Molecular interactions and electronic spectra. Marcel Dekker, New York

17. Siano DB, Metzler DE (1969) Band shapes of electronic spectra of complex molecules. J Chem Phys 51:1856-1861

18. Valeur B (2001) Molecular fluorescence-principles and applications. Wiley-VCH, Weinheim

19. Queiroz M-JRP, Castanheira EMS, Lopes TCT, Cruz YK, Kirsch G (2007) Synthesis of fluorescent tetracyclic lactams by a "one pot" three steps palladium-catalyzed borylation, Suzuki coupling (BSC) and lactamization. DNA and polynucleotides binding studies. J Photochem Photobiol A: Chem 190:45-52

20. Lide DR (ed) (2002) Handbook of chemistry and physics, 83rd edn. CRC, Boca Raton

21. Schmidt MW, Baldridge KK, Boatz JA, Elbert ST, Gordon MS, Jensen JH, Koseki S, Matsunaga N, Nguyen KA, Su S, Windus TL, Dupuis M, Montgomery JA (1993) General atomic and molecular electronic structure system. J Comput Chem 14:13471363

22. Jensen F (1999) Introduction to computational chemistry. Wiley, West Sussex

23. Grabowski ZR, Rotkiewicz K, Rettig W (2003) Structural changes accompanying intramolecular electron transfer: focus on twisted intramolecular charge-transfer states and structures. Chem Rev 103:3899-4031

24. Turro NJ (1978) Modern molecular photochemistry. Benjamin/ Cummings, Menlo Park

25. Papahadjopoulos D, Miller N (1967) Phospholipid model membranes. I. Structural characteristics of hydrated liquid crystals. Biochim Biophys Acta 135:624-638

26. Tilley L, Thulborn KR, Sawyer WH (1979) An assessment of the fluidity gradient of the lipid bilayer as determined by a set of $\mathrm{n}-(9$ anthroyloxy)fatty acids $(\mathrm{n}=2,6,9,12,16)$. J Biol Chem 254:25922594

27. Bahri MA, Heyne BJ, Hans P, Seret AE, Mouithys-Mickalad AA, Hoebeke MD (2005) Quantification of lipid bilayer effective microviscosity and fluidity effect induced by propofol. Biophys Chem 114:53-61

28. Strickler SJ, Berg RA (1962) Relationship between absorption intensity and fluorescence lifetime of molecules. J Chem Phys $37: 814$

29. Banerjee R (2001) Liposomes: applications in medicine. J Biomater Appl 16:3-21 